\title{
Proposições Conservadora e Crítica em Educação Ambiental: discussão das duas possibilidades em um mesmo espaço
}

Rodrigo Machado

\section{RESUMO}

A proposta deste trabalho é apresentar as Unidades de Conservação em regiões metropolitanas como relacionadas a ambientes diversos em um mesmo espaço: o núcleo protegido e seu entorno. Ainda, oferecer possibilidades para a abordagem de duas proposições antagônicas em Educação Ambiental, uma identificada como crítica, popular e transformadora; outra afeta a ações comportamentalistas com apelo a mudanças individuais. A discussão promovida no texto se pauta por apresentar o debate acerca do modelo de unidades de conservação no Brasil, as diferenças entre as perspectivas conservadora e emancipatória da Educação Ambiental e a ideia do turismo como recurso pedagógico, tendo como contexto o referido espaço que guarda dois ambientes em conflito: a preservação dos recursos naturais e a tensão resultante da expressão socioespacial de uma sociedade estratificada.

PALAVRAS-CHAVE: Unidade de Conservação, Turismo Pedagógico, Educação Ambiental

\section{Propositions and Conservative Criticism in Environmental Education: discussion of the two possibilities in the same space}

\section{ABSTRACT}

The purpose of this paper is to present the Protected Areas in metropolitan regions as related to different environments in the same space: the protected core and its surroundings. Also, it offers possibilities for dealing with two opposing propositions in Environmental Education; one identified as a critical, popular and transformative view, and the other seen as affecting the behavioral actions with an appeal to individual changes. The discussions held in the text is guided by the present debate about the model of protected areas in Brazil, the differences between the conservative and emancipatory perspectives of Environmental Education and the idea of tourism as a teaching resource, having as context the space that holds two environments in conflict: the preservation of natural resources and the tension resulting from the sociospatial expression of a stratified society.

KEYWORDS: Protected Areas, Tourism Educational, Environmental Education 


\section{Introdução}

Por se tratar de um texto que tem por objetivo discutir as possibilidades de se trabalhar a Educação Ambiental em unidades de conservação (UC) observando seus "entornos" imediatos, o caminho percorrido para sua elaboração considera a revisão de literatura e reflexão sobre as possibilidades identificadas no tema do trabalho. Iniciamos o percurso apresentando a ideia de unidades de conservação. Na sequência o texto aborda as possibilidades de se trabalhar a Educação Ambiental, esclarecendo a opção por uma das correntes que questiona o senso comum sobre a Educação Ambiental (EA).

Em seguida há a exposição sintética das alternativas que o turismo cria, desde que apoiado em conceitos identificados mais com o fenômeno social (do ponto de vista de inerente à necessidade humana e social de conhecer, de visitar e de receber) do que com a atividade econômica (que mercantiliza e hegemoniza aspectos do fenômeno, reduzindo-o).

\section{A ideia de Unidades de Conservação (UC)}

Nos últimos dois séculos, o mundo presenciou a aceleração das modificações e da destruição impostas aos ambientes naturais. Como forma de minimizar essa perda de biodiversidade, tem-se recorrido ao estabelecimento de Unidades de Conservação. O estabelecimento dessas áreas reservadas tem sido uma prática política adotada mundialmente. (BRITO, 2000, p.15)

Mesmo antes da criação das UC tal como hoje são conhecidas as áreas protegidas no Brasil, o interesse pela preservação da natureza, com ou sem alguma ação antrópica (humana), já era percebido (COSTA, 2002).

Segundo Wallauer (2003) a preocupação de "guardar" áreas naturais em benefício de atividades humanas, claramente sob uma visão construída socialmente da importância da natureza, inicia-se na Índia por volta do ano 252 a.C. onde havia áreas consideradas sagradas e, portanto, preservadas da ocupação humana, em um exemplo mais próximo de uma ligação espiritual entre "Homem e Natureza".

$\mathrm{Na}$ Europa, na Idade Média, havia espaços naturais preservados, então chamados "reservas de caça", e também áreas destinadas exclusivamente à extração e utilização da madeira como lenha, já pressupondo uma relação mais utilitária entre sociedade e natureza.

Séculos adiante, no mesmo continente, com o advento da Revolução Industrial (século XIX), surgem as áreas naturais como espaço de recreação para o homem moderno, bem como áreas naturais significativas para preservação em relação à própria 
capacidade de destruição da opção de desenvolvimento que a sociedade moderna já fazia. Embora se refira ao Homem, dando a ideia de espécie ${ }^{1}$, Toynbee (1987, apud WALLAUER, 2003) oferece a dimensão do impacto cultural e ambiental da Revolução Industrial:

[...] a Revolução Industrial é um acontecimento de magnitude biosférica [...] inverteu a relação do Homem e a biosfera. Ao fazer a Revolução Industrial, o Homem expôs a biosfera, inclusive ele próprio, a uma ameaça sem precedentes (TOYNBEE, 1987, apud WALLAUER, 2003, p.15).

A história dos parques, como áreas insulares de natureza preservada, remonta à segunda metade século XIX, quando em 1872 foi criada a primeira unidade de conservação do mundo, o "Yellowstone National Park", ou Parque Nacional Yellowstone, nos Estados Unidos da América (DIEGUES, 1996), dando origem àquilo que o autor denomina "modelo Yellowstone" de unidade de conservação.

As UC surgem claramente em função da expansão do modo de produção capitalista, então no auge da industrialização e urbanização como expressões do modelo de desenvolvimento baseado no crescimento, ampliando as fronteiras do espaço urbano/industrial que avançava deliberadamente sobre as antes naturais áreas (DIEGUES, 1996).

A criação do Parque Nacional de Yellowstone exemplifica o reconhecimento do poder de destruição do modo de produção capitalista. Tal unidade de conservação, segundo Costa (2002), foi fruto da união entre o então presidente dos EUA, Abraham Lincoln, e os movimentos de proteção à natureza. Reconhecia-se que a expansão industrial era nociva ao ambiente natural, e apresentava-se a criação de "ilhas de conservação", como alternativa preservacionista à natureza, ou seja, a sociedade capitalista reconhece que seu padrão de desenvolvimento literalmente consome recursos naturais e, no lugar de se repensar como sociedade, suas elites tomadoras de decisão optam pela criação de espaços naturais e protegê-los de si mesma.

A identificação de tais movimentos de proteção à natureza, na época de criação do modelo de preservação proposto pelas unidades de conservação, ocorria mais em função das belezas cênicas das áreas então protegidas, do que por suas qualidades intrínsecas, isto é, suas funções fundamentais à vida na Terra.

Preservava-se com o objetivo de garantir espaços insulares, ou ilhas de conservação. Também para apreciação das belezas que o meio natural, já mitificado, era capaz de proporcionar à sociedade moderna/industrial, submetida a uma lógica de produção predatória e de dominação da natureza e do próprio ser humano (reforçada pelo pensamento científico), lazer e recreação necessários para "recarregar" as energias para mais jornadas de trabalho e produção (DIEGUES, 1996), reproduzindo e ampliando o capital como padrão de relações sociais. 
Este modelo de UC estendeu-se ao resto do mundo. Países como Austrália (1879), Canadá (1885), Nova Zelândia (1894), África do Sul (dominada por colonizadores ingleses, em 1898), México (1889), Argentina (1903), Chile (1926), Equador (1934) Venezuela e Brasil (1937), entre outros, decidem adotar o mesmo modo de preservação de áreas naturais, independentemente do modelo de desenvolvimento existente nesses países, muito menos o grau de desenvolvimento de tal modelo.

No Brasil, de acordo com Costa (2002), a preocupação com áreas naturais preservadas surge com a proposta do engenheiro e político André Rebouças de criar os Parques Nacionais de Sete Quedas (PR) e da Ilha do Bananal (no Araguaia, atual Estado de Tocantins) em 1876, já inspirado pelos parques norte-americanos. Para a autora, os hortos e jardins botânicos, à época do Brasil-Colônia, já se configuravam como UC no País. Em 1934, com a criação do Código Florestal Brasileiro, fica a cargo da União e dos Estados "[...] a proteção das belezas naturais [...]" (WALLAUER, 2003).

A primeira unidade de conservação no Brasil é criada em 1937, no Estado do Rio de Janeiro, na área denominada Parque Nacional de Itatiaia, talvez como parte integrante da industrialização do País, no governo de Getúlio Vargas.

Assim como em outros países, nas áreas escolhidas para a criação dos parques não se levou em consideração a existência de populações tradicionais residentes há gerações e com um grau de ligação com o espaço não correspondente à mentalidade produtiva industrial e, portanto, não passível das desapropriações impostas pela proposta preservacionista do modelo de parques nacionais importado de países industrialmente mais avançados (DIEGUES, 1996).

É interessante observar que, segundo Wallauer (2003), as Unidades de Conservação no Brasil mesmo não considerando a necessidade imposta pelo grau de desenvolvimento do modo de produção no País, corresponde a uma lógica da expansão da fronteira de desenvolvimento, seja ele industrial ou agropecuário. Para a autora, a criação de UC deu-se, historicamente, do litoral para o interior do País, coincidindo com a ocupação humana promovida pela extensão da "franja" de desenvolvimento.

Na sequência do primeiro parque nacional brasileiro, surgem o Parque Nacional de Iguaçu (PR), e o Parque Nacional da Serra dos Órgãos (RJ), em 1939 (COSTA, 2002). Reforçando o caráter de preservação de características cênicas das paisagens naturais, pressupondo uma visão antropocêntrica da natureza, a Constituição de 1937, em seu artigo 134 afirma que cabe à Nação, aos Estados e Municípios a proteção aos "monumentos históricos, artísticos e naturais, assim como as paisagens ou locais particularmente dotados pela natureza [...]” (COSTA, 2002, p.19).

Nos anos 1960, houve a separação das áreas de preservação entre aquelas passíveis de exploração e as estritamente protegidas de qualquer ação humana. Foram nomeadas, respectivamente, as Florestas Nacionais, Estaduais e Municipais; e também os Parques Nacionais, Estaduais e Municipais e Reservas Biológicas (Id. Ibid.). 
Aqui cabe buscar mencionar a diferença entre os termos preservação e conservação. De acordo com Diegues (1996), o termo preservação refere-se à não utilização da natureza como recurso, já conservação induz a algum tipo de utilização, racional e sustentável.

Segundo Diegues (1996), a diferenciação entre os dois termos surge entre naturalistas como duas facções, desde a criação da primeira unidade de conservação no Brasil. Sendo a primeira, como já dito, proteger a natureza do desenvolvimento industrial, e a segunda utilizar os bens e serviços da natureza de forma racional, considerando a sociedade e modelo de desenvolvimento em que a UC insere-se.

Avançando mais rapidamente na história das unidades de conservação no Brasil, no início da década de 1990, surge o Projeto de Lei n. ${ }^{\circ} 2.892 / 92$ - que regulamenta o artigo $225, \S 1^{\circ}$, incisos I, II, III e IV da Constituição Federal. Este projeto redundou na Lei n. ${ }^{\circ}$ 9.985, que fez surgir o denominado pelos legisladores como sendo o Sistema Nacional de Unidades de Conservação da Natureza (SNUC). Depois de quase dez anos tramitando no Congresso Nacional, em julho de 2000, foi finalmente regulamentado o SNUC, sendo a primeira normatização nacional das áreas naturais protegidas por lei (COSTA, 2002).

De acordo com o SNUC, em seu parágrafo $2^{\circ}$, a definição de Unidades de Conservação é:

Espaço territorial e seus recursos ambientais, incluindo as águas jurisdicionais, com características naturais relevantes, legalmente instituídos pelo Poder Público, com objetivos de conservação e limites definidos, sob regime especial de administração, ao qual se aplicam garantias adequadas de proteção (WALLAUER, 2003).

Embora não seja intenção deste trabalho ponderar sobre a regulamentação do SNUC, cabe aqui uma consideração sobre o trecho "[...] características naturais relevantes [...]". Torna-se difícil saber quais os critérios utilizados para se afirmar a relevância de tais características naturais, seja para a geração presente, seja para as futuras, além de não se saber exatamente qual força move a afirmação, se é econômi$\mathrm{ca}$, ambiental, social etc. Mesmo se desenvolvendo alternativas de criação de UC pautadas pelo diálogo, ainda se observam tendências preservacionistas mais identificadas com a ideia de que qualquer intervenção humana na natureza é intrinsecamente negativa.

De acordo com Diegues (1996), a criação das UC a partir da expansão do modo de produção capitalista proporcionou a ratificação de uma relação dicotômica entre sociedade e natureza. A primeira, vendo-se como dominadora da segunda, põe-se fora do seu ambiente de origem, sendo forçada pelo modelo de apropriação capitalista de recursos naturais e também humanos, a enxergar a natureza como fundamen- 
talmente provedora de recursos a serem transformados em produtos e estes em riquezas; e como serviços naturais, a reprodução da fonte de recursos e a absorção de tudo o que é rejeitado pelo processo de desenvolvimento humano (MONTIBELLERFILHO, 2001).

\section{O entorno de Unidades de Conservação}

De acordo com o SNUC, o entorno das UC caracteriza-se como sendo "zona de amortecimento", ou seja, uma zona onde as atividades humanas devem ser controladas e "[...] sujeitas a restrições especificas, com o propósito de minimizar os impactos negativos sobre a unidade [...]' (BRASIL, 2000, p.02).

Tais zonas de amortecimento se localizam, portanto, em volta do núcleo de conservação (UC), não sendo necessariamente passíveis das mesmas restrições propostas pelo plano de manejo ${ }^{2}$ da unidade.

Conforme o art. 46 da Lei n. ${ }^{\circ}$ 9.985, de 18 de julho de 2000,

A instalação de redes de abastecimento de água, esgoto, energia e infra-estrutura urbana em geral, em unidades de conservação onde estes equipamentos são admitidos depende de prévia aprovação do órgão responsável por sua administração, sem prejuízo da necessidade de elaboração de estudos de impacto ambiental e outras exigências legais. (BRASIL, 2000, p.17)

O mesmo artigo, em seu parágrafo único, afirma que o mesmo se aplica às zonas de amortecimento das UC, quando de proteção integral ${ }^{3}$, "bem como às áreas de propriedade privada inseridas nos limites dessas unidades e ainda não indenizadas" (Id. Ibid.).

Ocorre que no mesmo espaço muitas é possível observar uma situação tensa entre uma proposta preservacionista que aposta na intangibilidade dos recursos naturais, cercando-os e protegendo-os da sociedade, e seu entorno ocupado por milhares de pessoas que, impossibilitadas por razões socioeconômicas de habitar centros urbanos, constroem fragilmente suas vidas em condições física, ambiental e legalmente inadequadas. Daí a menção a dois ambientes no mesmo espaço, ambos sendo expressões da mesma sociedade, resultantes do mesmo modo de produção. A própria Estratégia Nacional para Comunicação e Educação Ambiental (ENCEA), em seu documento preliminar (MMA, 2009), indica as UC como "cenários sociais". Conforme o documento: 
Políticas e projetos de comunicação e Educação Ambiental devem buscar uma compreensão das UCs que ultrapassem sua concepção como espaços de preservação de ecossistemas e de seus recursos naturais, mas considerá-las como espaços de relações socioambientais historicamente configurados e dinamicamente movidos pelas tensões e conflitos sociais, integrando-a ao desenvolvimento regional, fortalecendo as interações sociais e a participação cidadã de todos os segmentos envolvidos (MMA, 2009, p.09).

Se o contato com as UC proporcionado pelo turismo desconsiderar essa realidade tensa, perde-se a oportunidade de refletir sobre suas causas, bem como nosso papel na sociedade em que vivemos (e com a qual estabelecemos uma relação dialética e condicionarmos de sermos condicionados).

\section{O turismo e a Educação Ambiental a partir de concepções filosóficas opostas}

Aqui convém tratar da ideia de educação a partir da identificação e busca por compreendê-la como condicionada por algumas tendências filosóficas ou grupos de teorias. Partimos do pressuposto segundo o qual as concepções de Educação Ambiental, são tributárias de tendências filosóficas da própria educação.

A educação é um típico 'que fazer' humano, ou seja, um tipo de atividade que se caracteriza fundamentalmente por uma preocupação, por uma finalidade a ser atingida. A educação dentro de uma sociedade não se manifesta como um fim em si mesma, mas sim como um instrumento de manutenção ou transformação social. Assim sendo, ela necessita de pressupostos, de conceitos que fundamentem e orientem os seus caminhos. A sociedade dentro da qual ela está deve possuir alguns valores norteadores de sua prática (LUCKESI, 1994, p.31, Grifo nosso).

Segundo o autor podemos observar uma tendência filosófica a dar sentido à educação direcionada a redimir a sociedade, crendo que a escola e a educação têm o papel de corrigir algumas falhas de conduta dos indivíduos em uma sociedade tida como previamente adequada, orgânica e em harmonia. Saviani (1986) apresenta concepção semelhante, expondo uma ideia de educação acrítica, também dedicada a integrar os membros de uma sociedade harmoniosa, emergindo como um instrumento de correção de distorções, entendendo a marginalidade como um desvio individual, a ser, portanto, corrigido pela e na educação. Severino (2006) a denomina educação de uma perspectiva fundamentalmente "ética".

Um segundo grupo de teorias, denominadas "crítico-reprodutivistas" segundo Saviani (1986, p.8-9), concebe a educação "(...) como inteiramente dependente da 
estrutura social geradora de marginalidade, cumprindo aí a função de reforçar a dominação e legitimar a marginalização". Luckesi (1994) apresenta uma segunda tendência filosófica como compreendendo educação e a escola reproduzindo a sociedade, sendo uma abordagem crítica de ambas.

Um terceiro eixo de relacionamento entre filosofia e educação, segundo Luckesi (1994), se refere à educação como mediadora de um projeto social, posicionando a escola como um meio de transformar a sociedade. Além da identificação da educação como um dos meios de transformar a sociedade, a contribuição de Saviani (1991).é também propositiva, com a apresentação de sua "Pedagogia Histórico-crítica".

Ainda com relação à superação das duas tendências de conceber a educação como externas e naturalmente dadas ao indivíduo, Severino (2006) apresenta que o panorama atual encontra-se em transformação. De uma educação baseada em valores éticos e se voltando, na história, à razão e o ser humano como central no processo de compreensão e apropriação do mundo de maneira instrumental, a uma educação a investir em uma razão emancipatória. Ou seja, nas palavras do autor trata-se de "uma nova forma de se compreender a educação: nem mais sob a prevalência de uma teleologia ética nem mais sob a perspectivação política. Tanto a ética como a política estão sendo questionadas como referências básicas da educação" (SEVERINO, 2006, p.629). A partir da concepção de educação construída por Adorno, Severino (2006) apresenta que:

Trata-se de uma formação imanente do sujeito da história real da desalienação na história presente, alienada. É que na sociedade industrializada do capitalismo, a educação crítica do indivíduo, base de sua formação emancipatória, encontra-se travada, realizando-se apenas como adaptação, ou seja, como semiformação, travamento da experiência emancipadora (SEVERINO, 2006, pp. 632-633).

Finalizando a discussão em seu texto, o autor afirma que

(...) a ideia de formação cultural dá à educação uma finalidade intrínseca de cunho mais antropológico do que ético ou político, num sentido estrito. Até para transformar os indivíduos em pessoas éticas e políticas, a educação precisa efetivar-se como formação cultural. No entanto, em si mesma, a educação não tem como garantir, diretamente, que as pessoas se tornem éticas - ela é uma experiência eminentemente pessoal a revolução política é uma experiência exclusiva do sujeito coletivo em sua especificidade (SEVERINO, 2002, p.633).

Werlang (2005, p.18) ao dissertar sobre a obra de Adorno a respeito da dimensão emancipatória da educação, afirma que "a noção de educação apresenta-se co- 
mo necessidade para barrar os processos semiculturais, por conseguinte, o desenvolvimento e reaparecimento de toda e qualquer expressão da barbárie". Contudo, mais adiante o autor desenvolve uma reflexão acerca das limitações impostas pela própria sociedade.

A educação, embora seja um processo marcado pela dupla tensionalidade entre o significado adaptativo de inserção na vida cultural e social e a dimensão de estranhamento desses mesmos processos quando o sujeito se distancia criticamente para sentir-se capaz de interferir significativamente na elaboração de sua existência e mundo, no contexto do capitalismo tardio, necessita de ênfase emancipatória, já que seu aspecto de adaptação geralmente permanece como absoluto (WERLANG, 2005, p.26).

Essa tendência filosófica crítica a condicionar a finalidade da educação tem por perspectiva "compreender a educação como mediação de um projeto social" (LUCKESI, 1994, p.48). Para Saviani (1986), trata-se de uma teoria crítica da educação, à qual "(...) se impõe a tarefa de superar tanto o poder ilusório (que caracteriza as teorias não-críticas) como a impotência (decorrente das teorias críticoreprodutivistas) colocando nas mãos dos educadores uma arma de luta capaz de permitir-lhes o exercício de um poder real, ainda que limitado" (SAVIANI, 1986, pp.3536). Tal projeto ou possibilidade de luta não redimem nem reproduzem a sociedade da qual a escola é parte. Têm o papel de servir de meio, contribuindo seja para conservar ou transformar a sociedade. Frente às duas tendências já expostas, uma otimista e outra pessimista em relação ao "poder" da educação sobre a sociedade, a ideia de educação como mediadora de um projeto social tende a compreender a organização da sociedade como social e historicamente constituídas. Essa tendência crítica serve de referência tanto para negar a ideia de Educação Ambiental hegemônica em nossa sociedade, como também para subsidiar sua perspectiva emancipatória.

Compreendendo a Educação Ambiental como tributária de ao menos duas perspectivas filosóficas das expostas acima (ética, redentora ou acrítica; da formação cultural, transformadora, histórico-crítica), a seguir a discussão ruma para a exposição de duas correntes da EA. Uma é mais identificada como conservadora, apostando na correção de "desvios comportamentais" essencialmente no âmbito do indivíduo. Outra mais afeta à superação da proposta individualista de mudanças de postura, considerando as contradições e conflitos como inerentes à sociedade e, principalmente, reforçando a consciência crítica e a ação coletiva como pressupostos básicos para a transformação social na direção de padrões mais adequados de relacionamento entre sociedade e ambiente.

Ao contrário do que é convencional nas práticas educativas que, ao vislumbrarem as UC como lócus de Educação Ambiental (EA) as compreendem como ambiente "natural", é preciso não tratar tais áreas protegidas como destacadas da esfera cultu- 
ral na qual vivemos. Grun (1996) aponta o "cartesianismo" contido em propostas de visitas a parques e outras áreas naturais com a intenção de aproximação com a esfera natural. E questiona: "como é possível obter algum sucesso em tais programas se muitas vezes eles se pautam nos mesmos principios que pretendem criticar?" (GRUN, 1996, p.56). Aqui o autor se refere à dicotomia reforçada entre as esferas cultural e natural a partir da ideia de que visitas a áreas naturais promoveriam uma suposta consciência ecológica.

Loureiro e Cunha (2008, p.241) apresentam que o

(...) pensamento educativo dominante, que influencia profundamente propostas peda-gógicas implantadas em atividades de Educação Ambiental em UCs, é marcado por uma visão que afirma como verdade o princípio segundo o qual nos desdobramos na história por meio de determinações essenciais. Com isso, a ação prática não tem sentido condicionante e nem a realidade histórica pode ser alterada pela atividade de nossa espécie (LESSA, 2001). Logo, o que podemos fazer é, por intermédio da educação, ajustar os nossos comportamentos para garantir o bom funcionamento da sociedade e a harmonia com a natureza.

A partir de tal noção de educação, sobretudo aquela direcionada a se dedicar à relação entre sociedade e ambiente, observamos uma extrema simplificação e imputação ao ser humano como espécie uma essência ruim, egoísta, destrutiva (LOUREIRO; CUNHA, 2008).

O fato de algumas UC se encontrarem em certa medida integradas ou muito próximas à estrutura da cidade possibilita compreender que ambas as esferas fazem parte de um só todo, e de que as próprias pessoas são integradas a esse todo complexo. Realmente, as UC são ótimos espaços educativos. São oportunidades de se promover reflexões e discussões sobre o contexto social, cultural, econômico e político que gera a necessidade de nossa sociedade, organizada da forma que é e produzindo do modo que produz, criar e proteger áreas e recursos naturais dela mesma. Contudo, se uma finalidade de promover visitas a uma UC se identificar com alguma proposta de Educação Ambiental, aí entra outra questão: de qual concepção de educação se está falando?

Essa discussão se torna relevante porque dependendo da corrente de Educação Ambiental a que estão vinculadas as atividades desenvolvidas dentro de uma UC (EA conservadora ou EA crítica), seja de proteção integral ou mesmo de uso sustentável, o turismo pouco poderá contribuir para a ideia de conservação ambiental. $A$ isso se relaciona, também, nos perguntarmos se o modelo preservacionaista tem efeitos de longo prazo, uma vez que não se discute a estrutura de organização da sociedade e o modo de produção que criam as condições objetivas de degradação ambiental (e consequente necessidade de preservação de determinadas áreas naturais). À ideia 
de "preservação dos recursos naturais" se atrela uma EA conservadora e comportamentalista (GUIMARÃES, 2004), limitada à transmissão de informações que enaltecem uma natureza e individualidade fetichizadas (LOUREIRO, 2006; LOUREIRO et al. 2009) e apartadas da sociedade. Um verdadeiro mito moderno (DIEGUES, 1996) que pouca relação guarda com a realidade cotidiana de quem visita ou faz turismo em UC.

Aparentemente faz parte do senso comum compreender as UC, a legislação que as envolve e as possibilidades de acesso e gestão são naturalmente dados, ou seja, se assemelham a um aglomerado de artigos normatizadores que devem ser conhecidos por todos, simplesmente (e isso seria algum indício de conhecimento e competência...).

A questão aqui não se refere a ser favorável ou contrário à ideia de UC. Nas atuais circunstâncias pelas quais nossa sociedade é responsável, uma das poucas formas efetivas de proteger recursos naturais de nós mesmos é criando UC. No entanto, devemos estar atentos ao contexto multidimensional, complexo, social e histórico como condicionante fundamental dessa forma de compreender a questão da preservação e da conservação, sabendo que somos sujeitos históricos. Como dizia Paulo Freire: "o mundo não é, o mundo está!"

Isso pode ser entendido como educação (inclusive considerando-a circunstancialmente ambiental) e é aí que se pode ter o turismo com grande possibilidade de contribuir não somente com a conservação de UC, mas dos ambientes "externos" a elas, inclusive onde realmente moramos e transformamos diretamente.

O espaço ao qual se refere este trabalho, como já mencionado, guarda dois ambientes de regiões metropolitanas, especificamente de São Paulo. Um interno à UC e que trabalha um viés conservador de Educação Ambiental, ou seja, mais preocupado em expor aos seus interlocutores passivos a importância de se preservar da própria dinâmica da sociedade os recursos naturais que ainda restam.

O outro ambiente, externo e imediato à UC, por vezes oferece uma paisagem que se pode apresentar-se desoladora. Seja do ponto de vista ecológico ou da perspectiva social. Trata-se de um local ao qual se dirigem membros da sociedade sem condições de partilhar melhores condições ambientais e de vida. Nele moram pessoas que também fazem parte da cidade e de sua dinâmica socioespacial, certamente integrados à economia. Por ser resultante do modo como a sociedade se organiza e do modo de produção hegemônico, formando o que chamamos de periferia, guarda condições privilegiadas para se perguntar: porque aquelas pessoas estão ali, disputando espaço com o parque? Por que não residem em áreas dotadas de melhor infraestrutura urbana? Isso, inclusive, antes de nos perguntarmos por que razão exercem alguma pressão sobre a área protegida.

Outra possibilidade de composição da paisagem em ambiente externo às UC é de determinadas classes sociais, de padrão de vida e de consumo mais elevados, beneficiando-se da valorização imobiliária gerada a partir do reconhecimento da qualidade ambiental proporcionada pela área preservada. Será que a relação entre UC e en- 
torno ocupado por classes altas e médias-altas é tensa? Que tipo de relação pode ser observada entre aquela representação do padrão de ocupação urbana e regiões ocupadas por famílias pobres? Quais as implicações sociais da alta valorização de terrenos imediatos a UC?

A proposta pedagógica que emerge de tais condições ambientais geram experimentações, vivências, reflexões e olhares críticos sobre nós mesmos - individualmente e como seres sociais - e sobre como a sociedade trata (e poderia tratar) determinadas questões ambientais. Portanto, visa a transformações pessoais, mas com a perspectiva de mudanças coletivas.

Essa é a ideia de Educação Ambiental que se propõe às UC e entorno como espaço de envolvimento com discussões e práticas que apontem a transformações sociais. Tal ideia se apoia na necessidade de promover circunstâncias que trabalhem, com a população, residente e visitante, o que Jacobi (2005) identifica como motivos para a desvinculação das pessoas com o estado do meio e com as possibilidades de mudança. Segundo o autor,

A postura de dependência e de não responsabilidade da população decorre principalmente da desinformação, da falta de consciência ambiental e de um déficit de práticas comunitárias baseadas na participação e no envolvimento dos cidadãos, que proponham uma nova cultura de direitos baseada na motivação e na co-participação na gestão do meio ambiente, nas suas diversas dinâmicas (JACOBI, 2005, p.241).

Layrargues (2004, p.07) expõe que "o adjetivo ambiental designa uma classe de características que qualificam essa prática educativa, diante desta crise ambiental que ora o mundo vivencia". Crise ambiental resultante de questões econômicas e sociais observadas de maneira crítica por perspectivas teóricas não surgidas no bojo das discussões sobre Educação Ambiental, mas sim desde a identificação, por parte dos (visitantes, estudantes, moradores, monitores, educadores e educandos), das contradições entre capital e trabalho. Uma das características que subsidiam a adjetivação "ambiental" da ação educativa, segundo Layrargues, se refere à educação convencional que tradicionalmente, tal qual os demais sistemas sociais, não tem sido direcionada à sustentabilidade. Sem prescindir da necessária transformação da educação formal, a proposta deste texto a complementa e dá sua contribuição, inclusive em termos metodológicos e também didáticos, às próprias instituições educacionais formais.

Guimarães (2004) trata a Educação Ambiental não como relativa à evolução de algo anterior, mas sim como contraposição e superação de algo existente. Na realidade, o autor se remete a um dos posicionamentos existentes para conceber Educação Ambiental, uma vez que sua concepção não é consensual. Daí que Carvalho (2004) 
apresenta a questão da multiplicidade de "educações ambientais". Conforme a autora,

(...) as práticas agrupadas sob o conceito de Educação Ambiental têm sido categorizadas de muitas maneiras: Educação Ambiental popular, crítica, política, comunitária, formal, não formal, para o desenvolvimento sustentável, conservacionista, socioambiental, ao ar livre, para solução de problemas entre tantas outras (CARVALHO, 2004, p.15).

Tais denominações têm origem em diferentes contextos, relações dinâmicas de forças sociais e culturais, "poderes e contrapoderes" que condicionam a produção de cada proposta, "(...) onde o destinatário também constitui o artefato que a ele é endereçado" (ibidem).

No que se refere à Educação Ambiental crítica abordada pela autora em seu texto, duas marcas fundadoras são expostas, contidas nos adjetivos "ambiental" e "crítica". O adjetivo "ambiental" se justifica e se legitima "(...) enquanto aspiração legítima, sócio-historicamente situada, que sinaliza para o reconhecimento da importância de uma Educação Ambiental na formação dos sujeitos contemporâneos" (CARVALHO, 2004, p.18). O adjetivo "crítica" se sustenta no reconhecimento da insuficiência - embora fundamental - da adjetivação da ação educativa como "ambiental". Se o que se pretende é promover a perspectiva de uma práxis, faz-se necessária outra escolha, de caráter político.

Considerando a educação como sendo intrinsecamente envolvida na "(...) vida, na história e nas questões urgentes de nosso tempo, a Educação Ambiental acrescenta uma especificidade: compreender as relações sociedade-natureza e intervir sobre os problemas e conflitos ambientais" (idem, p.18).

Neste sentido, o projeto político-pedagógico de uma Educação Ambiental Crítica seria o de contribuir para uma mudança de valores e atitudes, contribuindo para a formação de um sujeito ecológico. Ou seja, um tipo de subjetividade orientada por sensibilidades solidárias com o meio social e ambiental, modelo para a formação de indivíduos e grupos sociais capazes de identificar, problematizar e agir em relação às questões socioambientais, tendo como horizonte uma ética preocupada com a justiça ambiental (CARVALHO, 2004, p.18-19).

Sintetizando a proposta da Educação Ambiental crítica, ainda de acordo com a autora ao adotar a perspectiva de transformação social necessária para uma "justiça ambiental", observa-se a recusa tanto à opção exclusiva por uma espécie de individualização. Essa tendência a considerar somente mudanças individuais sugere que a mudança virá da soma de mudanças individuais, do cada um fazendo sua parte. A mesma consideração crítica se dá no extremo oposto, em que se observa a generalização e despersonalização do coletivo, gerando a ideia de que a transformação social 
é anterior àquela individual. Ao passo que é insuficiente nos responsabilizarmos como indivíduos por processos sociais e historicamente constituídos, não é possível escaparmos da responsabilidade de intervir nos mesmos processos como sujeitos históricos.

A ideia de Educação Ambiental crítica trabalha com a intenção de desenvolver processos nos quais os indivíduos, uma vez envolvidos, tomam consciência do que fazem, como o fazem e por que o fazem, sem perder de vista que não o fazem sozinhos, e sobretudo, não o transformam sozinhos. "Assim a Educação Ambiental deve ser acima de tudo um ato político voltado para a transformação social" (JACOBI, 2003, p.196), contrapondo-se ao que Guimarães (2004) apresenta como Educação Ambiental conservadora que, refletindo os paradigmas da sociedade moderna, reforça a crença que a transmissão de conhecimentos e informações corretas concorre à transformação do indivíduo (e que esta transformação individual basta).

Loureiro (2005) expõe o que denomina como dois blocos de práticas e compreensão do que vem a ser a Educação Ambiental e seu papel. De um lado se observa um bloco conservador ou comportamentalista e, de outro, um bloco chamado de transformador, crítico ou emancipatório. O primeiro teria entre suas características centrais a educação entendida em sua dimensão individual, baseada em vivências práticas, despolitizadas e comportamentalistas; não problematizam os processos históricos de que resulta a problemática socioambiental que vivemos e que discute a necessidade de consumir menos sem relação com o modo de produção que define nosso padrão de consumo, além de responsabilizar o ser humano como espécie, naturalizando a discussão (LOUREIRO, 2005).

Já o segundo bloco se apoia em características mais identificadas com a reflexão e o debate sobre o modo como nos relacionamos em sociedade e com as demais formas de vida no planeta; politiza e torna pública a complexidade inerente a qualquer discussão sobre problemas ambientais, reconhecendo a participação social como intrínseco à EA; não compreende o conhecimento ambiente como única finte de saber, mas sim a exposição dialógica deste com outras formas de conhecimento (popular, tradicional etc.); possui um posicionamento político de buscar a ruptura com padrões, valores e práticas sociais contrários ao bem estar público, à equidade e à solidariedade (LOUREIRO, 2005).

Nesse sentido, observa-se que "a Educação Ambiental, em específico, ao educar para a cidadania, pode construir a possibilidade da ação política, no sentido de contribuir para formar uma coletividade que é responsável pelo mundo que habita" (SORRENTINO, et al., 2005, p.287). Complementa-se: com a perspectiva inclusive de iniciar a busca pela promoção de um diálogo entre sociedade e Estado na direção de construir políticas públicas.

Assim, emerge a ideia de se compreender as unidades de conservação como loci privilegiados não somente para desempenhar um "(...) papel fundamental como ferramenta para a gestão, o manejo e a proteção destas áreas, (...) propiciando co- 
nhecimento e experimentação direta com a natureza, motivando o interesse e a integração das populações com a natureza" (FUNDAÇÃO FLORESTAL, 2009, s/p). Podem - e devem - ser tomadas como um grande tema gerador/espaço educador de debates na mesma proporção, contextualizando as próprias unidades em relação aos processos sócio-históricos dos quais são também expressão, como apresenta Loureiro et al. (2009) em relação à busca por não reproduzirmos ações - prenhes de ingenuidade ou de má fé - em nossa prática educativa. Outra contribuição do autor se manifesta na seguinte afirmação:

(...) coerentemente com o método marxiano de compreensão e intervenção na realidade e diante das múltiplas possibilidades metodológicas, os objetivos de aprendizagem consistiriam basicamente em:

(a) entender a complexidade do ambiente, ou seja, superar uma leitura reducionista que enfatiza seus aspectos biológicos ou estritamente culturais e desconsidera as relações de determinação entre as esferas social e ecológica e as dimensões econômica e política, contribuindo para superar processos materiais de alienação e reinserir o ser humano em seu tempo e espaço (ser histórico, naturalmente humano ou humanamente natural);

(d) entender que "sua realidade" é tratada de forma fragmentada/ desarticulada pelo Estado, por meio de diferentes órgãos/políticas setoriais, o que contribui para o esvaziamento do poder de pressão da sociedade (necessidade) (LOUREIRO et al., 2009, p. 91).

Trata-se, portanto, de contextualizar o espaço em questão, dicotomizado em ambientes distintos, porém resultantes de dinâmicas similares, considerando outras dimensões da tão evocada "questão ambiental". Tais dimensões perpassam pela reflexão sobre a percepção cultural do que vem a ser tomado como "natureza", bem como os condicionantes sociais, históricos e políticos que nos influenciam em nossa percepção, ação e interação com o meio.

\section{Estudo do meio e turismo pedagógico de base local: subsídios para a educação crítica}

$\mathrm{Na}$ ideia de turismo pedagógico de base local, o conceito-chave é o Turismo de Base Local ou Comunitário, acompanhado de outro conceito também importante: o Turismo Pedagógico ou Educativo, que lança mão do estudo do meio como método para promover um ambiente formativo tanto para visitantes como para moradores. Compreendendo o turismo "ao lugar onde se vive " como a criação de uma oportunidade de deslocamento, tanto físico como intelectual (de olhares, de compreensões, de ideias etc.) e observando a necessidade de transgredir a noção de educação como formação conservadora e adequação àquilo que se julga absolutamente verdadeiro - e que promove assim a aceitação pacífica "do lugar de cada um" em nossa sociedade -, a 
seguir serão expostos os meios para buscar tornar isso possível, bem como algumas premissas básicas para não concorrer à sua deterioração por conta de incoerências.

Os estudos do meio se apresentam neste trabalho baseando-se na exposição de Pontuschka (2004). Segundo a autora, embora o conceito de estudo do meio sofra variações de acordo com as diferenças de escolas, professores e da própria localização no tempo, trata-se tanto de técnica e método, como também um fim em si mesmo. Apoiando-se em discussões promovidas por autores que se debruçaram sobre o tema a partir da década de 1950, Pontuschka (2004) apresenta que o estudo do meio pode ser compreendido

[...] como fim [...], ou seja, o do valor que um estudo do meio tem para que alunos assimilem conhecimentos relacionados às diferentes disciplinas escolares por meio do vivido; como método [...] a formação do educando como pessoa e como cidadão (PONTUSCHKA, 2004, p. 255).

Quanto às discussões e apresentações do estudo do meio como técnica, a autora identifica que se tratavam, na realidade, de referências ao estudo do meio como método, uma vez que serviam às mesmas proposições metodológicas apontadas na citação acima e, sobretudo, a compreensão de que o estudo do meio guarda uma complexidade que uma simples técnica não suporta.

Além da reflexão do estudo do meio servir tanto como fim em si, ao promover a apreensão de saberes disciplinares a partir de situações vividas em campo, como também um método, ao se tomar o estudo do meio como importante ação educativa que concorre à formação do ser humano e do cidadão trata-se de uma proposta importante por conta de sua gênese. Pontuschka (2004) apresenta que os estudos do meio têm origem em atividades semelhantes das escolas anarquistas do início do século XX. Mais especificamente, atividades identificadas com o pensamento destas escolas sobre educação. "A escola deveria ser um espaço do debate, de diálogo que levasse os alunos a pensar com suas próprias cabeças" (Idem, p. 251). Do ponto de vista da práxis, a ideia de estudo do meio se reforça considerando-se a afirmação apresentada por Imbert (1984, p.3): "não é o educador que ensina, mas sim a situação". Uma definição de estudo do meio é apresentada por Pontuschka, Paganelli e Cacete (2007). Afirmam as autoras que

O estudo do meio é uma metodologia de ensino interdisciplinar que pretende desvendar a complexidade de um espaço determinado extremamente dinâmico e em constante transformação, cuja totalidade dificilmente uma disciplina escolar pode dar conta de compreender (PONTUSCHKA; PAGANELLI; CACETE, 2007 p. 173). 
Em sendo a escola um espaço identificado com a reprodução de saberes, atitudes e comportamentos tidos inicialmente pelo Estado - e hoje predominantemente pelo mercado - como aceitáveis em um cidadão, torna-se problemático imprimir a essa mesma escola uma educação essencialmente crítica e emancipatória. Embora esta seção não se proponha a discutir as condições da escola como instituição social, ao menos apresenta alternativas concretas de articular tais dificuldades institucionais com outras práticas educativas. Tais práticas se direcionam a dar cabo do estudo do meio de forma séria e comprometida com suas características de "fim em si" e de método por meio do denominado turismo pedagógico.

Esse tipo de prática de turismo é essencialmente vinculado ao ensino básico e, por certo, restrito a um público identificado com as escolas e outras instituições de ensino. Contudo, pode e deve ser estendido a outros níveis de ensino, inclusive propostas de educação não formal em nível superior. Vinha et. al. (2005), por exemplo, demonstra preocupação em apontar pressupostos apoiados nas discussões propostas por Freinet ${ }^{5}$ para situar os parâmetros de um turismo pedagógico. A própria etimologia da palavra pedagogia sugere "direção ou educação de crianças" (CORDEIRO, 2007, p. 18).

Silveira, Martins e Vieira (2008) aceitam e expõem acriticamente a finalidade da educação vinculada à formação de um indivíduo produtivo, integrado à divisão do trabalho e, portanto, interessante ao capital e demonstrando a premente apropriação de possibilidades emancipatórias. As autoras destinam ao turismo pedagógico o papel de "qualificar" tal conformação com o mundo do trabalho. Além disso, o turismo pedagógico serviria também à educação e "conscientização" de residentes em destinações turísticas sobre a "importância do desenvolvimento do turismo", principalmente nas crianças. Imbert (1984) produz a crítica à insistência em tal foco nas crianças para se buscar "transmitir o que é correto". Evocando o paradigma do superior/inferior, o autor questiona a ideia de tomar a criança como algo vazio ou "em branco", e o mestre como o responsável por preencher tal vazio ou imprimir todo seu conhecimento aos "pequenos". Loureiro (2009) questiona a ideia de a educação "conscientizar" e transmitir informações e comportamentos tidos como adequados do ponto de vista de determinada parte da sociedade (que os sabe e os produz) em relação à outra parte (que não sabe e não teria condições de constituir seus próprios referenciais e compreensões).

Não é difícil identificar que a mesma visão que se tem das crianças em relação àquilo compreendido por falta de conhecimento é aplicado automaticamente a quaisquer pessoas, mesmo adultas, quando se parte do pressuposto no qual de um lado há os que sabem; de outro os que ignoram completamente.

Raykil e Raykil (2005, p.7) relacionam de forma mais abrangente o turismo com o processo educativo: 
Turismo Pedagógico busca oferecer aos estudantes a oportunidade de aprender na prática o que foi visto nos conteúdos abordados em sala de aula. Através da utilização desse mecanismo facilitador no processo ensino aprendizagem o que mais chama a atenção é a possibilidade de se trabalhar efetivamente a interdisciplinaridade.

Partindo desta afirmação pode-se compreender, também, que a ideia de turismo pedagógico serve, inclusive, a um processo educativo não obrigatoriamente de crianças, mas de qualquer faixa etária. Os mesmos autores lembram que o turismo pedagógico possibilita a promoção do sentido daquele conhecimento que está sendo trabalhado, de maneira interdisciplinar e contextualizada - ou um "mundo de referências palpáveis" (RAYKIL; RAYKIL, 2005, p. 08). Isso não significa que o estudo do meio serve à intenção de reforçar, simplesmente, o conteúdo trabalhado em sala de aula. Trata-se de proporcionar o confronto entre teoria e realidade e, também, dar sentido e articulação entre diferentes saberes e disciplinas na maioria das vezes fragmentadas no currículo institucional. O turismo pedagógico se aproxima da ideia exposta sobre estudo do meio ao se considerar a afirmação de Taveira (2007, p. 255): "no caso do Turismo Pedagógico, a atividade [é] fundamentada na aula-passeio de Freinet, que tem como principal objetivo facilitar o aprendizado a partir de experiências turísticas sem perder seu caráter pedagógico". Contudo, não se trata de um "segmento ou nicho de mercado" ou "modalidade", como expõe o mesmo autor. Podese compreender o turismo pedagógico como um conceito que abriga características próximas àquelas anteriores ao denominado turismo moderno e mercantilizado, mas não as mesmas. Concepção de turismo inclusive antagônica àquela tida como "moderna".

Quanto ao desenvolvimento das vivências promovidas pelo turismo pedagógico, Jesus, Wenceslau e Bortolança (2007) e Perinotto (2008) apresentam que devem ser planejadas por profissionais de diferentes áreas, ressaltando que não se trata de excursões ou passeios, mas sim deslocamentos de caráter formativo, nos quais se busca a criação de situações de aprendizagem, relacionadas aos conteúdos trabalhados em outras circunstâncias do processo educativo.

Em se tratando de turismo pedagógico de base local em um bairro periférico, torna-se importante a compreensão de que os moradores, além de visitantes externos àquele espaço na periferia da metrópole, envolvam-se com a proposta. Estes também compõem o público a ser considerado nos estudos do meio, na busca por promover o deslocamento do olhar e da compreensão que se tem daquele ambiente no qual residem. Por que aquele espaço é identificado como periferia (tanto em termos socioeconômicos como geográficos)? Quais são os sentidos de tal identificação? Por que aquele bairro existe e a que interesses pode corresponder?

Por turismo de base local ou comunitário entende-se a necessidade de envolvimento dos residentes tanto no planejamento e desenvolvimento da atividade turística, 
bem como, principalmente, no direcionamento dos benefícios diretos da atividade, sejam eles econômicos, financeiros, culturais, ambientais, sociais etc. Ou seja, "mais que um simples tipo de atividade turística praticada pelos visitantes, representa um modelo de gerenciamento turístico de caráter principalmente inclusivo e que tem como desdobramento desse aspecto o oferecimento de produtos diferenciados" (PINHEIRO, 2006, p. 31). A mesma autora (2007, p. 483) aponta "elementos caracterizadores" e "elementos estratégicos" como categorias para seu entendimento. "No primeiro grupo estão presentes as categorias essenciais à caracterização de uma experiência de gerenciamento comunitário do turismo, ao passo que no segundo encontram-se elementos facilitadores desta prática" (idem, p. 486). Essa concepção de turismo atrela-se ao que Coriolano $(2001,2003)$ denomina "eixo de desenvolvimento" oposto àquele entendido como globalizado e voltado às necessidades sociais locais.

Os elementos caracterizadores são: protagonismo comunitário, organização comunitária e rentabilidade para a comunidade. Já os elementos estratégicos são aqueles aspectos julgados pela autora como importantes para uma boa e efetiva realização do turismo comunitário. São eles: turismo como atividade econômica complementar, posse da terra pela comunidade, conservação ambiental e cultural.

\section{Algumas considerações}

Para finalizar o texto - e não o debate - apresenta-se a seguir algumas considerações para sintetizar a discussão realizada neste trabalho. A intenção, como já dito, é provocar uma reflexão relativa ao assunto que vincula o turismo, a Educação Ambiental e as unidades de conservação. Afinal, quando nos referimos às UC, nos referimos a elas ou a um modelo de preservação? Quando pensamos em Educação Ambiental, de que educação estamos tratando? E no momento em que compreendemos o turismo como um importante meio de promoção da Educação Ambiental em UC, qual a concepção de turismo que faz parte do senso comum a ponto de nos guiarmos por ele e homogeneizarmos nossa compreensão desse fenômeno? Como esse mesmo turismo está organizado para exercer papel tão caro à educação e às próprias UC? Há coerência nisso tudo?

Inicialmente, ao tratamos de turismo, Educação Ambiental e UC, torna-se importante discutir também sobre essa última. Ter em conta as condições sociais e históricas que influenciam tanto na criação e definição de áreas a ser protegidas, como também, e principalmente, a dinâmica socioespacial e produtiva que determina tal modelo de proteção de recursos naturais. Questões como o histórico de criação das UC no Brasil, qual visão do ambiente externo a uma UC (sobretudo aquele ocupado por populações pobres) se pode ter a partir do lado interno dos gradis, portões e guaritas, a relação tensa entre o núcleo preservado onde "nada pode" e o entorno algumas vezes em que "tudo pode".

Quanto à proposta de EA que se pretende lançar mão, esta resulta tanto da a- 
bordagem às UC e seu complexo contexto, como também às suas finalidades. É preciso refletir sobre o que se quer alcançar levando e conduzindo visitantes às UC.

Buscando manter coerência entre o que se pensa e o que se pratica, o meio de integrar as pessoas e os ambientes visitados, a concepção e a forma de organização do turismo apresentam-se relevantes, uma vez que há discussões importantes a subsidiar outra maneira de estruturar localmente uma atividade mais identificada com a noção de fenômeno social do que simplesmente trocas comerciais que mercantilizam as relações humanas.

Quando nos referimos ao turismo como importante meio de contribuição à conservação de áreas protegidas por meio da Educação Ambiental, é preciso realizar algumas reconsiderações com base em reflexões teóricas e conceituais. Sobre as UC, o turismo e a Educação Ambiental, os entendemos como determinações "normais" de nossa sociedade "naturalmente constituída", ou como expressões de dinâmicas sociais, modo de produção e modelo de desenvolvimento sendo, a partir disso, plataformas e recursos expressivos para a reflexão crítica e construção de projetos transformadores? Cremos que a segunda possibilidade é mais adequada em se tratando de orientação teórica para o desenvolvimento de processos que envolvam os três objetos tratados nesse texto.

\section{Referências Bibliográficas}

ADORNO, T.W. Educação e emancipação. Rio de Janeiro: Paz e Terra, 1995.

BRASIL. Lei n. ${ }^{\circ 9} .985,18$ de julho de 2000. Sistema Nacional de Unidades de Conservação. Brasília, DF, 19 jul. de 2000. Disponível em: <http://www.mma.gov.br/port/sbf/ index.cfm>. Acesso em: 22 set. 2003.

Decreto n. ${ }^{\circ} 4.340,22$ de agosto de 2002. Regulamenta artigos da Lei $n .{ }^{\circ}$ 9.985, de 18 de julho de 2000. Brasília, 23 de ago. de 2002. Disponível em: < http:// www.mma.gov.br/port/sbf/index.cfm>. Acesso em: 22 set. 2003.

BRITO, M. C. W. Unidades de conservação: intenções e resultados. São Paulo: ANNABLUME, 2000.

CARVALHO, I. C. M. Educação Ambiental Crítica: nomes e endereçamentos da educação. In: LAYRARGUES, P. P. Identidades da Educação Ambiental brasileira / Ministério do Meio Ambiente. Diretoria de Educação Ambiental. Brasília: Ministério do Meio Ambiente, pp.13-24, 2004.

CORDEIRO, J. Didática. São Paulo: Contexto, 2007. 
CORIOLANO, L. N. M. Os limites do desenvolvimento e do turismo. Boletim Goiano de Geografia. 21 (2): 25-45. jun./dez.2001.

cal. Fortaleza: Editora Premius, 2003.

. (org.). O Turismo de Inclusão e o Desenvolvimento Lo-

COSTA, P. C. Unidades de conservação: matéria prima do ecoturismo. São Paulo: Aleph, 2002.

DIEGUES, A. C. O mito moderno da natureza intocada. São Paulo: Hucitec, 1996.

ESTRATÉGIA Nacional de Comunicação e Educação Ambiental no SNUC (ENCEA). Ministério do Meio Ambiente. Disponível em: <http://www.mma.gov.br/estruturas/ educamb/ arquivos/encea docprel.pdf>. Acesso em 31 ago 2009.

FUNDAÇÃO FLORESTAL. A Educação Ambiental nas unidades de conservação gerenciadas pela Fundação Florestal. Disponível em: <http:// www.fflorestal.sp.gov.br/educacaoambientalConceito.php>. Acesso em 01 set 2009.

GRUN, M. Ética e Educação Ambiental: a conexão necessária. Campinas: Papirus, 1996.

GUIMARÃES, M. Educação Ambiental Crítica. In: LAYRARGUES, P. P. Identidades da Educação Ambiental brasileira / Ministério do Meio Ambiente. Diretoria de Educação Ambiental. Brasília: Ministério do Meio Ambiente, pp.25-34. 2004.

IMBERT, F. Para uma práxis pedagógica. Brasília: Plano Editora, 1984.

JACOBI, P. R. Educação Ambiental, cidadania e sustentabilidade. Cadernos de Pesquisa, 118: pp.189-205, 2003.

JACOBI, P. R. Educação Ambiental: o desafio da construção de um pensamento crítico, complexo e reflexivo. Revista Educação e Pesquisa, 31, (2): pp.233-250, 2005.

JESUS, D. L.; WENCESLAU, M. E.; BORTOLANÇA, M. D. Turismo Pedagógico como forma de sustentabilidade para a Reserva Indígena de Dourados. In: II Seminário Povos Indígenas e Sustentabilidade, 2007, Campo Grande. Seminário Povos Indígenas e Sustentabilidade: saberes e práticas interculturais na universidade. Campo Grande, UCDB, v. 01. p. 26-27, 2007.

LAYRARGUES, P. P. Identidades da Educação Ambiental brasileira / Ministério do Meio Ambiente. Diretoria de Educação Ambiental. Brasília: Ministério do Meio Ambiente, 2004. 
LOUREIRO, C. F. B. Complexidade e dialética: contribuições à práxis política e emancipatória em Educação Ambiental. Revista Educação e Sociedade, vol. 26, (93), pp.1473-1494, 2005.

LOUREIRO, C.F.B.; TREIN, E.; TOZONI-REIS, M.F.C.; NOVICKI, V. Contribuições da teoria marxista para a educação ambiental crítica. Cad. CEDES [online], vol.29, n.77, 2009.

LOUREIRO, C. F. B. Crítica ao fetichismo da individualidade e aos dualismos na Educação Ambiental. Educar, Curitiba, n. 27, p. 37-53, 2006.

MONTIBELLER-FILHO, G. 0 mito do desenvolvimento sustentável. Florianópolis: Ed. da UFSC, 2001.

LOUREIRO, C. F. B.; CUNHA, C. C. Educação Ambiental e gestão participativa de Unidades de Conservação: elementos para se pensar a sustentabilidade democrática. Revista Ambiente \& Sociedade. Campinas, v. 11, n. 2, 2008.

LUCKESI, C.C. Filosofia da Educação. São Paulo: Cortez, 1994.

PERINOTTO, A. R. C. Turismo pedagógico: uma ferramenta para Educação Ambiental. Caderno Virtual de Turismo (COPPE-UFRJ), v. 8, p.100, 2008.

PINHEIRO, L. L. O turista aprendiz: uma viagem na dimensão pedagógica da atividade turística em Pipa e na Prainha do Canto Verde. Monografia (Graduação do Curso de Bacharelado em Turismo). João Pessoa, Universidade Federal da Paraíba, 2006.

- Turismo comunitário: alguns apontamentos conceituais. Anais do X Encontro Nacional de Turismo com Base Local. Tomo III. João Pessoa, 2007, pp. 481-490.

PONTUSCHKA, N. N. O conceito de estudo do meio transforma-se... em tempos diferentes, em escolas diferentes, com professores diferentes. In: VESENTINI, J.W. (org.). O ensino de Geografia no século XXI. Campinas: Papirus, 2004.

PONTUSCHKA, N. N.; PAGANELLI, T. I.; CACETE, N. H. Para ensinar e aprender Geografia. Coleção Docência em Formação. São Paulo: Cortez, 2007.

RAYKIL, E. B.; RAYKIL, C. Turismo pedagógico: uma interface diferencial no processo ensino aprendizagem. Revista Global Tourism - Periódico de Turismo, v. 2, n. 1, 2005. 
Machado, $R$.

SAVIANI, D. Educação e democracia. 10a ed. São Paulo: Cortez; Autores Associados, 1986.

. Pedagogia Histórico-crítica: primeiras aproximações. $7^{\text {a }}$ ed. São Paulo: Cortez Editora e Editora Autores Associados, 1991.

SEVERINO, A. J. A busca do sentido da formação humana: tarefa da Filosofia da Educação. Revista Educação e Pesquisa, São Paulo, v.32, n.3, p. 619-634, set-dez, 2006.

SILVEIRA, C. R. F. D; MARTINS, P. C. S.; VIEIRA, F. S. Turismo Pedagógico em Dourados/MS: uma atividade educacional. $V$ Seminário de Pesquisa em Turismo do MERCOSUL - SeminTUR. Turismo: Inovações da Pesquisa na América Latina. Universidade de Caxias do Sul (UCS), Caxias do Sul, RS, 2008.

SORRENTINO, M.; TRAJBER, R.; MENDONÇA, P.; FERRARO-JUNIOR, L. A. Educação Ambiental como política pública. Revista Educação e Pesquisa 31 (2): 285-299, 2005.

TAVEIRA, M. S. Turismo pedagógico: planejamento e gestão em pequenas e médias localidades. Anais do X Encontro Nacional de Turismo com Base Local. Tomo III. João Pessoa, pp. 254-302, 2007.

UNG, Universidade Guarulhos. Relatório da Parte I do Diagnóstico Ambiental para o manejo sustentável do Núcleo Cabuçu, do Parque Estadual da Cantareira e áreas vizinhas do Município de Guarulhos. Guarulhos, UnG, 2003.

VINHA, M. L.; GARCIA, M.D.; ROMÃO, C.; OLIVEIRA, D.L.Y.; MARIN, F.; BOTELHO, F.; GIACOMO, F.; SCACCHETTI, M.C.F. O turismo pedagógico e a possibilidade de ampliação de olhares. Hórus - Revista de Humanidades e Ciências Sociais Aplicadas, Ourinhos, SP, Nº3, 2005.

WAINBERG, J. Cidades como sites de excitação turística. In: CASTROGIOVANNI, A.C. Turismo Urbano. São Paulo: Contexto, 2000.

WALLAUER, M. T. B. Sistema Nacional de Unidades de Conservação - SNUC. In: ENCONTRO PRESENCIAL DA FUNIBER, 2003, Florianópolis. Aula Presencial - Arquivos com as Palestras. Florianópolis: FUNIBER, 2003. Disponível em: <http:// www.funiber.org.br/encontro-downloads2003.php>. Acesso em: 30 jun. 2003.

WERLANG, J.C. Educação, cultura e emancipação: estudo em Theodor Adorno. Passo Fundo, RS: EdIFIBE, 2005. 
NOTAS:

${ }^{1}$ Preferimos nos referir à sociedade no lugar de simplesmente ao Homem. A primeira dá a ideia de complexidade da sociedade, abarcando condicionantes históricos, políti$\cos$, culturais etc. O segundo tende a naturalizar a relação entre sociedade e natureza, reforçando a dicotomização e biologizando qualquer debate, como se o ser humano como espécie, e não suas opções econômicas, políticas, culturais etc., fosse determinante no processo de degradação planetária.

2“[...] documento técnico mediante o qual, com fundamento nos objetivos gerais de uma unidade de conservação, se estabelece o seu zoneamento e as normas que devem presidir o uso da área e o manejo dos recursos naturais, inclusive a implantação das estruturas físicas necessárias à gestão da unidade." (BRASIL, 2000, p.02).

${ }^{3} \mathrm{O}$ objetivo básico das UC de proteção integral seria a preservação da natureza (e não a conservação), uma vez que somente é admitido o uso indireto dos seus recursos naturais, exceto nos casos previstos em lei. (BRASIL, 2000).

${ }^{4}$ Aqui o "lugar onde se vive" diz respeito a duas perspectivas iniciais: uma relativa ao local no qual realmente residem moradores afastados de áreas metropolitanas centrais; outro à própria metrópole, espaço de habitação de grande parte da população.

${ }^{5}$ Segundo Cordeiro (2007, p.180), "Freinet considerava a criança como um ser social, participante de uma comunidade, e não como um indivíduo. Assim, suas propostas pedagógicas insistem no trabalho coletivo em praticamente todas as etapas, inclusive na avaliação, que deveria ser feita em conjunto pelos alunos e pelo professor".

Rodrigo Machado: Mestrando em Educação pela Universidade de São Paulo.

Email: rodrigomachado@usp.br

Link para o currículo Lattes: http://lattes.cnpq.br/8158716621756456

Data de submissão: 28 de outubro 2009.

Data do aceite: 14 de dezembro de 2009. 